\title{
Making an IMPACT: The Story of a Medical Student-Designed, Peer-Led Healthy Eating and Physical Activity Curriculum
}

\author{
Avik Chatterjee, ${ }^{1}$ Thomas N. Rusher, ${ }^{2}$ Julia Nugent, ${ }^{2}$ Kenneth W. Herring, \\ Lindsey M. Rose, ${ }^{2}$ Dean Nehama, ${ }^{2}$ and Natalie D. Muth ${ }^{3}$ \\ ${ }^{1}$ Department of Population Medicine, Harvard Medical School and Harvard Pilgrim Health Care Institute, Boston, MA 02215, USA \\ ${ }^{2}$ University of North Carolina School of Medicine, Chapel Hill, NC 27516, USA \\ ${ }^{3}$ Children's Primary Care Medical Group, San Diego, CA 92130, USA \\ Correspondence should be addressed to Avik Chatterjee; avc031@mail.harvard.edu
}

Received 3 December 2014; Revised 3 March 2015; Accepted 3 March 2015

Academic Editor: Sumantra Ray

Copyright (C) 2015 Avik Chatterjee et al. This is an open access article distributed under the Creative Commons Attribution License, which permits unrestricted use, distribution, and reproduction in any medium, provided the original work is properly cited.

\begin{abstract}
Despite the importance of healthful dietary choices in combating the childhood obesity epidemic, neither primary and secondary schools nor medical schools provide adequate nutrition education. In 2005, two medical students at the University of North Carolina started the Improving Meals and Physical Activity in Children and Teens (IMPACT) program, which utilized a peer-educator model to engage medical students and high school students in teaching 4th graders about healthy eating and physical activity. Over the years, medical student leaders of IMPACT continued the program, orienting the curriculum around the 5-2-1-0 Let's Go campaign, aligning the IMPACT curriculum with North Carolina state curricular objectives for 4 th graders and engaging and training teams of health professional students to deliver the program. The IMPACT project demonstrates how medical and other health professional students can successfully promote nutrition and physical activity education for themselves and for children through communitybased initiatives. Ongoing efforts are aimed at increasing family participation in the curriculum to maximize changes in eating and physical activity of IMPACT participants and ensuring sustainability of the organization by engaging health professional student participants in continuing to improve the program.
\end{abstract}

\section{Introduction}

Rates of childhood obesity have tripled in recent decades with estimates that $30 \%$ of American children will be obese by 2030 if the epidemic is not stopped [1]. Despite the increasingly apparent relationship between certain eating behaviors, obesity, and chronic disease and death [2,3], less than half of American medical schools are providing the recommended amount of nutrition education [4]. Nutrition education for medical students is especially important because, in the authors' experience, medical students can make important contributions to improving nutrition and physical activity and improving community health even very early in their careers.

In the fall of 2004, two of the authors (Avik Chatterjee and Natalie D. Muth) started medical school at the University of North Carolina at Chapel Hill (UNC). At that time, before the Let's Move campaign [5] and the 2013 United
States Department of Agriculture school food guidelines [6], childhood obesity was already an epidemic problem nationally [7] and in North Carolina [8]. As a former high school teacher (Avik Chatterjee) and a registered dietitian with training in public health (Natalie D. Muth), both saw the potential for a school-based intervention to improve eating behaviors $[9,10]$ and recognized the power of peer teaching to improve health behaviors among children [11]. Together they developed a healthy eating and physical activity education curriculum for elementary school students led by high school students. They named this curriculum IMPACT-Improving Meals and Physical Activity in Children and Teens.

\section{The IMPACT Intervention}

In the spring of 2005, Avik Chatterjee and Natalie D. Muth partnered with UNC School of Medicine Pediatric faculty 
and a local school district. Working closely with the Director of Healthy Living of the school district the team identified an elementary school and a high school located within short walking distance of each other. Concurrently, Avik Chatterjee and Natalie D. Muth applied for and received the Albert Schweitzer fellowship to support their intervention.

The IMPACT curriculum consisted of twelve-hour-long, once-weekly lessons [12]. Approximately half of each lesson was designated for nutrition education and half for physical activity. The nutrition education and physical activity materials were assembled from nutrition education programs (such as MyPyramid) [13] and physical activity programs (such as the CDC's VERB program) [14] that were available online at that time.

Avik Chatterjee and Natalie D. Muth worked closely to establish and nurture partnerships among the school district, medical school, students and families, and local communities. At the high school they worked closely with health education teachers to recruit and train high school student educators to deliver the curriculum. In the community they established relationships with local businesses, including an athletic club to provide the space for the trainings and gym memberships as incentives to high school student educators. Local grocery stores and other vendors also generously provided assistance with healthy snacks for the curriculum sessions. Elementary school teachers and 4th-grade teachers allowed the intervention into two of their classrooms. The students and families were also highly involved. Each week, students had a homework assignment that required family involvement, and at the end of the curriculum students and families came together at the school for a celebration with healthy snacks.

Evaluation was an important aspect of the program. Students in the two intervention classes and two control classes had body mass index (BMI) measured and filled out surveys about their knowledge, attitudes, and behaviors on certain target eating behaviors. The intervention went exceptionally smoothly and was well-received by high school student peer educators and 4 th-grade participants. While there was no significant difference in the change in BMI percentile for age between the intervention and control groups $(-1 \%$ in the intervention students compared to control students; $P=0.59$ ), in a difference-in-differences analysis students in the intervention group were more likely to know how many servings of fruits and vegetables they should eat ( $+20 \%$ compared with controls; $P=0.01)$ and also reported eating more fruits and vegetables (+0.85 servings/day compared with controls; $P=0.05)$. All $P$ values are for the interaction term between the outcome and the presence of the intervention in a linear regression model adjusted for sex, age, baseline value of the variable, and BMI percentile, except in the case where BMI percentile itself is the outcome [12].

\section{IMPACT over Time}

As authors Natalie D. Muth and Avik Chatterjee progressed in their medical education, the IMPACT curriculum took varying forms. After a brief hiatus, UNC medical students revamped and relaunched the curriculum with a focus on the intervention in elementary schools.

The IMPACT Program was revived in 2012 by authors Julia Nugent and Lindsey M. Rose with the goals of providing education on healthful living to elementary children in order to be involved in community-wide preventative medicine. Upon entering medical school at UNC in 2012, Julia Nugent was invigorated by the idea of IMPACT, especially with a background in biochemistry and strong interest in nutrition. As a former 5th-grade teacher who saw how unhealthful living negatively affected her students and community, Lindsey M. Rose sought out IMPACT. Since IMPACT was not active, they reinstated this important program as a means of both promoting additional nutrition education for health professional students and providing a meaningful way to interact with the community in which they lived.

Under the guidance of an experienced faculty mentor at UNC School of Public Health, IMPACT made significant changes to the curriculum, incorporating the 5-2-1-0 recommendations as the foundation of the curriculum, teaching teams of health professional students to provide direct education to 4 th-grade elementary students, and providing lecture series for health professional student-teachers focused on clinical nutrition.

The backbone of IMPACT's lessons is the 5-2-1-0 message, a component of the Let's Go initiative first implemented in Portland, Maine, in 2006 [16-19]. The creators of Let's Go reasoned that a consistent message, in addition to onthe-ground promotion, could raise awareness of healthy lifestyles and begin to address the childhood obesity problem in their community. The 5-2-1-0 mnemonic presents four daily recommendations: "eat 5 or more fruits and vegetables," "limit screen time to two hours or less," "participate in 1 hour of physical activity," and "aim for 0 sugary drinks" [20]. When this message was taught in 56 school settings in Portland, Maine, in addition to systematic changes and community, participants were found to consume more fruits and vegetables and less sugary drinks and report that they were more aware of the 5-2-1-0 model [21]. Students are encouraged to follow the 5-2-1-0 program via weekly trackers and paper communication with their parents.

Fourth-grade classrooms in North Carolina were specifically targeted because their science curriculum includes learning about healthful living as well as specific disease processes that are more common in people with poor diet and exercise habits. IMPACT lessons were designed to align with the North Carolina Essential Standards for Nutrition and Physical Activity and Science (Table 1).

The IMPACT program utilizes teaching teams comprised of health professional students (medical students, dental students, nursing students, pharmacy students, and public health students) who work with the fourth-grade teams of two local elementary schools to lead a six-week-long program. The students, mostly medical students, are recruited through activity fairs, student government newsletters, and an introductory interest meeting. Classroom group assignments are made considering past experience in classrooms or working with this age group as well as volunteer preference in forming their own teaching groups. Weekly teaching groups 
TABLE 1: North Carolina Essential Standards and Clarifying Objectives for 4th-grade nutrition and physical activity and science addressed by the IMPACT curriculum [15].

\begin{tabular}{ll}
\hline NC Essential Standard & Objective addressed \\
\hline $\begin{array}{l}\text { 4.NPA.1: Apply tools (MyPlate, Food Facts Label) to } \\
\text { plan healthy nutrition and fitness. }\end{array}$ & $\begin{array}{l}\text { 4.NPA.1.1: Plan meals using MyPlate. } \\
\text { 4.NPA.1.3: Use the Food Facts Label to plan meals and } \\
\text { avoid food allergies. }\end{array}$ \\
\hline $\begin{array}{l}\text { 4.NPA.2: Understand the importance of consuming a } \\
\text { variety of nutrient dense foods and beverages in } \\
\text { moderation. }\end{array}$ & $\begin{array}{l}\text { 4.NPA.2.1: Compare unhealthy and healthy eating } \\
\text { patterns, including eating in moderation. }\end{array}$ \\
\hline & $\begin{array}{l}\text { 4.NPA.2.2: Explain the effect of eating healthy and } \\
\text { unhealthy breakfasts and lunches. }\end{array}$ \\
$\begin{array}{ll}\text { 4.NPA.3: Understand the benefits of nutrition and } \\
\text { fitness to disease prevention. }\end{array}$ & $\begin{array}{l}\text { 4.NPA.3.1: Explain how nutrition and fitness affect } \\
\text { cardiovascular health. }\end{array}$ \\
& $\begin{array}{l}\text { 4.NPA.3.2: Summarize the association between caloric } \\
\text { intake and expenditure to prevent obesity. }\end{array}$ \\
& $\begin{array}{l}\text { 4.L.2.1: Classify substances as food or nonfood items } \\
\text { based on their ability to provide energy and materials } \\
\text { for survival, growth, and repair of the body. } \\
\text { minerals, and exercise. }\end{array}$ \\
& $\begin{array}{l}\text { 4.L.2.2: Explain the role of vitamins, minerals, and } \\
\text { exercise in maintaining a healthy body. }\end{array}$ \\
\hline
\end{tabular}

NPA: nutrition and physical activity.

L: life science.

consist of three to four teachers, and there is typically a pool of substitute volunteers that are contacted as needed. Before entering the classroom, all volunteers attend a training session in order to review the curriculum and discuss classroom management strategies. Throughout the program they are encouraged to collaborate and tailor the lessons to best suit their respective classrooms. Lessons follow a similar basic structure over a six-week timeline, beginning with a brief interactive lecture followed by a variety of small group exercises to reinforce key lesson concepts. Lessons culminate with a physical activity, such as a "Dance Off," to reinforce the emphasis on exercise.

Evaluation continued to be an important part of IMPACT. Pre- and postprogram exams were given to evaluate IMPACT's efficacy; the tests consisted of 6 multiple choice questions, one evaluating a main point of each of the six lessons. The mean, standard deviation, standard error of the mean, and a two-tailed $t$-test with unequal variance calculated in Microsoft Excel (Durham, NC) were used to statistically evaluate the efficacy of the IMPACT program. A trend towards improvement in exam score was seen but, in paired $t$-test analysis, did not reach statistical significance (Figure 1; preprogram test score 77\% SD 9.2, postprogram test score $84 \%$ SD 2.9; $P$ value $0.13, n=30$ ). The accumulated data in addition to feedback from the elementary school teachers identified areas for curriculum improvement. Another important source of evaluation was the informal feedback from the IMPACT volunteers. Their reports help guide future lesson planning to benefit both the students and the volunteer teachers.

In addition to elementary school outreach, the IMPACT organization provides supplemental nutrition education for motivated UNC health professional students with seminars provided by UNC faculty members focused on topics with clinical and public health relevance. Presentations entitled

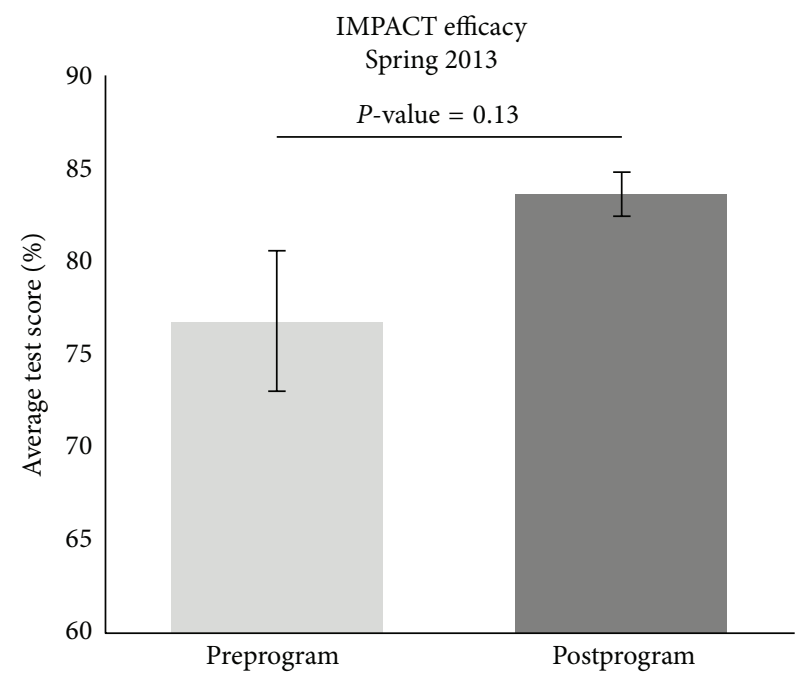

FIGURE 1: Average test scores and standard errors of a 6-question multiple choice test given before and after IMPACT program, evaluating the efficacy of the program in teaching key lesson concepts $(n=$ 30). $P$ value is for a paired $t$-test.

"Nutrition Myths," "Nutrition in Oncology," "Adolescent Eating Disorders", and "How to Counsel Parents of the Obese Child" have stimulated valuable interdisciplinary discussions on nutrition in medicine.

\section{Lessons Learned}

The IMPACT experience provides a model of how medical students, with the right support and mentorship, can create and implement a successful intervention to improve eating behaviors and physical activity in the community. Combining 
nutrition education and physical activity, peer education, and family and community engagement are the cornerstones of IMPACT's continued success.

However, a current limitation of the IMPACT curriculum is the lack of parental involvement in lessons. Parental nutrition education can be a strong determinant in a child's health habits [22, 23], and therefore increased parental involvement has become a major goal of current co-president authors Thomas N. Rusher and Kenneth W. Herring for improvement of IMPACT. While there are constraints to only address a small subset of 4 th graders without broader parental and community involvement, there is intrinsic value for these students and their families to think about their own health and nutrition within the framework of an organized curriculum.

Throughout the years, another important lesson that the IMPACT story has illustrated is the challenge and value in establishing a sustainable organization. Therefore, an essential goal of IMPACT has been to address sustainability as an organization by gaining official recognition with the university administration, establishing organization bylaws and philosophy, and creating Standard Operating Protocols to ensure smooth transition between leaders. Every member of IMPACT team has contributed substantially to the program, making the importance and privilege of its continued existence even more apparent.

As obesity and other nutrition-related conditions and diseases continue to affect children and adults in America, nutrition education that allows medical students to engage in prevention will be increasingly important. Furthermore, with a call for increased nutrition and exercise education in the medical school curriculum [24], the value of teaching in solidifying one's own understanding, and the growing need for clinic-community integration [25], programs such as the IMPACT program provide a unique and fulfilling opportunity for medical students to gain competencies required for physicians to solve today's greatest health challenges.

The IMPACT program at UNC will continue during the 2014-2015 academic year and, we predict, for years to come. The authors and the members of the IMPACT team will share curriculum materials and their experience with others interested in organizing similar initiatives.

\section{Conflict of Interests}

The authors have no conflict of interests to declare.

\section{Acknowledgments}

The authors would like to thank their faculty mentor, Dr. Martin Kohlmeier, without whom the IMPACT intervention would not have been possible. The authors would also like to thank the Albert Schweitzer Fellowship and the Whitehead Society at the University of North Carolina School of Medicine. Dr. Chatterjee received funding support from an Institutional National Research Service Award (T32HP12706), the Ryoichi Sasakawa Fellowship Fund, and the Department of Population Medicine at Harvard Medical School and Harvard Pilgrim Health Care Institute.

\section{References}

[1] K. M. Flegal, D. Carroll, B. K. Kit, and C. L. Ogden, "Prevalence of obesity and trends in the distribution of body mass index among US adults, 1999-2010," The Journal of the American Medical Association, vol. 307, no. 5, pp. 491-497, 2012.

[2] A. Bellavia, S. C. Larsson, M. Bottai, A. Wolk, and N. Orsini, "Fruit and vegetable consumption and all-cause mortality: a dose-response analysis," The American Journal of Clinical Nutrition, vol. 98, no. 2, pp. 454-459, 2013.

[3] A. Pan, Q. Sun, A. M. Bernstein, M. B. Schulze, J. E. Manson, and M. J. Stampfer, "Red meat consumption and mortality: results from 2 prospective cohort studies," Archives of Internal Medicine, vol. 172, no. 7, pp. 555-563, 2012.

[4] K. M. Adams, K. C. Lindell, M. Kohlmeier, and S. H. Zeisel, "Status of nutrition education in medical schools," The American Journal of Clinical Nutrition, vol. 83, no. 4, pp. 941S-944S, 2006.

[5] Let's Move!, 2014, http://www.letsmove.gov/.

[6] USDA, USDA Unveils Historic Improvements to Meals Served in America's Schools New Standards Will Improve the Health and Wellbeing of 32 Million Kids Nationwide, USDA, Fairfax, Va, USA, 2012, http://www.usda.gov/wps/portal/usda/usdahome? contentid $=2012 / 01 / 0023 . \mathrm{xml}$.

[7] C. L. Ogden, M. D. Carroll, B. K. Kit, and K. M. Flegal, "Prevalence of obesity and trends in body mass index among US children and adolescents, 1999-2010," Journal of the American Medical Association, vol. 307, no. 5, pp. 483-490, 2012.

[8] Percentage of Overweight and Obese Children through Years of Age, NC-NPASS 1995-2012, 2011, http://www.eatsmartmovemorenc.com/Data/Texts/Chart_Obesity_Overweight trends 1995-2012.pdf.

[9] F. T. Shaya, D. Flores, C. M. Gbarayor, and J. Wang, "Schoolbased obesity interventions: a literature review," Journal of School Health, vol. 78, no. 4, pp. 189-196, 2008.

[10] M. Sharma, "School-based interventions for childhood and adolescent obesity," Obesity Reviews, vol. 7, no. 3, pp. 261-269, 2006.

[11] A. R. Mellanby, J. B. Rees, and J. H. Tripp, "Peer-led and adult-led school health education: a critical review of available comparative research," Health Education Research, vol. 15, no. 5, pp. 533-545, 2000.

[12] N. D. Muth, A. Chatterjee, D. Williams, A. Cross, and K. Flower, "Making an IMPACT: effect of a school-based pilot intervention," North Carolina Medical Journal, vol. 69, no. 6, pp. 432-440, 2008.

[13] MyPyramid [Internet], Wikipedia, 2014, http://en.wikipedia .org/wiki/MyPyramid.

[14] CDC, VERB: CDC's Youth Campaign, CDC, 2014, http://www .cdc.gov/youthcampaign/.

[15] North Carolina Essential Standards: Health Education-Grades 3-5 [Internet], 2011, http://www.dpi.state.nc.us/acre/standards/ new-standards/.

[16] N. F. Krebs and M. S. Jacobson, "Prevention of pediatric overweight and obesity," Pediatrics, vol. 112, no. 2, pp. 424-430, 2003.

[17] C. S. Berkey, H. R. Rockett, A. E. Field et al., "Activity, dietary intake, and weight changes in a longitudinal study of 
preadolescent and adolescent boys and girls," Pediatrics, vol. 105, no. 4, p. E56, 2000.

[18] A. Must, E. E. Barish, and L. G. Bandini, "Modifiable risk factors in relation to changes in BMI and fatness: what have we learned from prospective studies of school-aged children?" International Journal of Obesity, vol. 33, no. 7, pp. 705-715, 2009.

[19] B. A. Swinburn, I. Caterson, J. C. Seidell, and W. P. T. James, "Diet, nutrition and the prevention of excess weight gain and obesity," Public Health Nutrition, vol. 7, no. 1, pp. 123-146, 2004.

[20] V. W. Rogers and E. Motyka, "5-2-1-0 Goes to school: a pilot project testing the feasibility of schools adopting and delivering healthy messages during the school day," Pediatrics, vol. 123, no. 5, pp. S272-S276, 2009.

[21] V. W. Rogers, P. H. Hart, E. Motyka, E. N. Rines, J. Vine, and D. A. Deatrick, "Impact of let's go! 5-2-1-0: a community-based, multisetting childhood obesity prevention program," Journal of Pediatric Psychology, vol. 38, no. 9, pp. 1010-1020, 2013.

[22] K. E. Rhee, C. W. DeLago, T. Arscott-Mills, S. D. Mehta, and R. K. Davis, "Factors associated with parental readiness to make changes for overweight children," Pediatrics, vol. 116, no. 1, pp. e94-e101, 2005.

[23] E. M. Perrin, J. C. Jacobson Vann, J. T. Benjamin, A. C. Skinner, S. Wegner, and A. S. Ammerman, "Use of a pediatrician toolkit to address parental perception of children's weight status, nutrition, and activity behaviors," Academic Pediatrics, vol. 10, no. 4, pp. 274-281, 2010.

[24] Teaching nutrition and physical activity in medical school: training doctors for prevention-oriented care, 2014, http:// greenvillemed.sc.edu/doc/Nutrition-and-Physical-ActivityInitiative.pdf.

[25] W. Dietz and D. Bradley, Integrated Clinical and Social Systems for the Prevention and Management of Obesity, Washington, DC, USA, 2014, http://www.iom.edu/ /media/Files/Activity Files/Nutrition/Obesity-Roundtable/Innovation_Collaboratives/About_the_ICSSPMO_IC.pdf. 

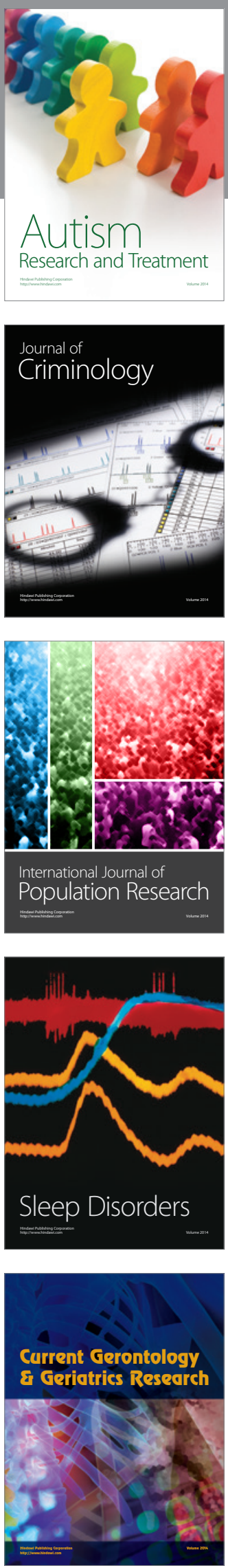
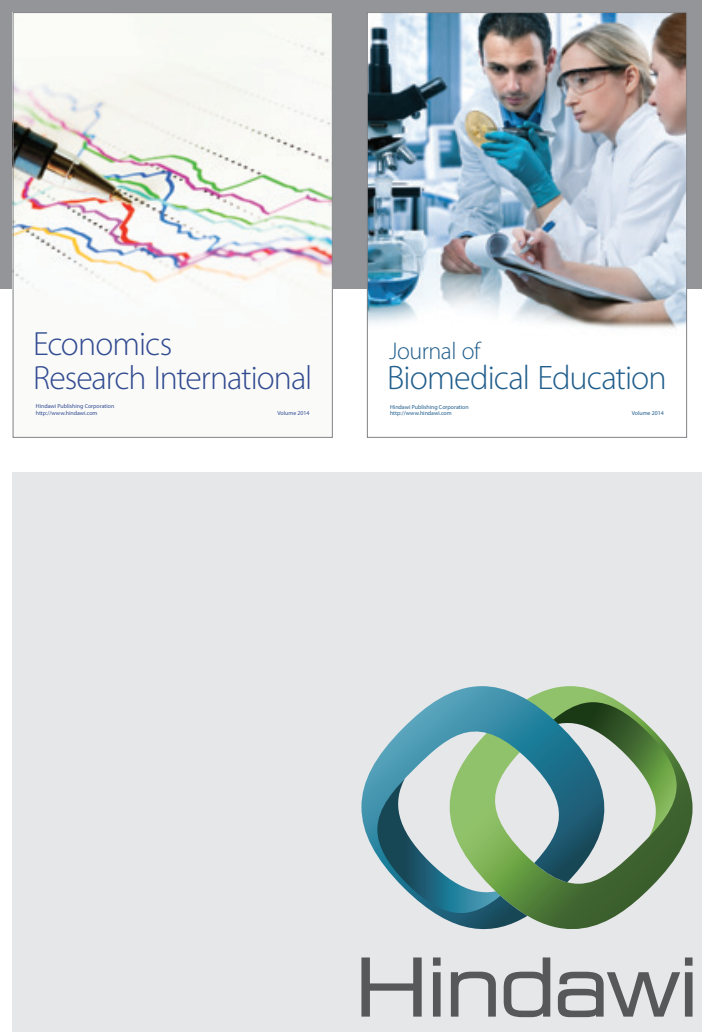

Submit your manuscripts at

http://www.hindawi.com
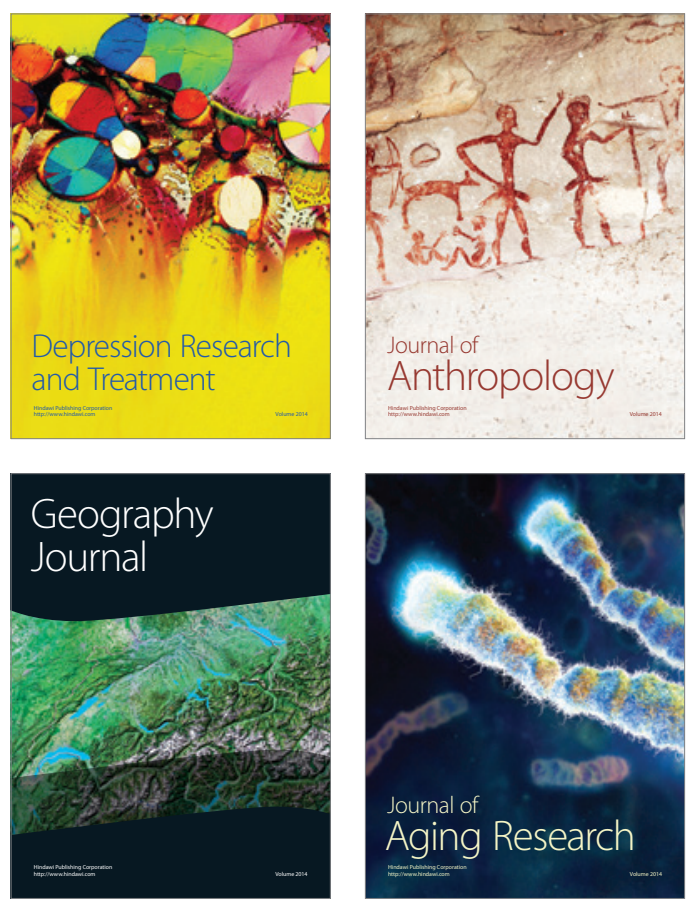
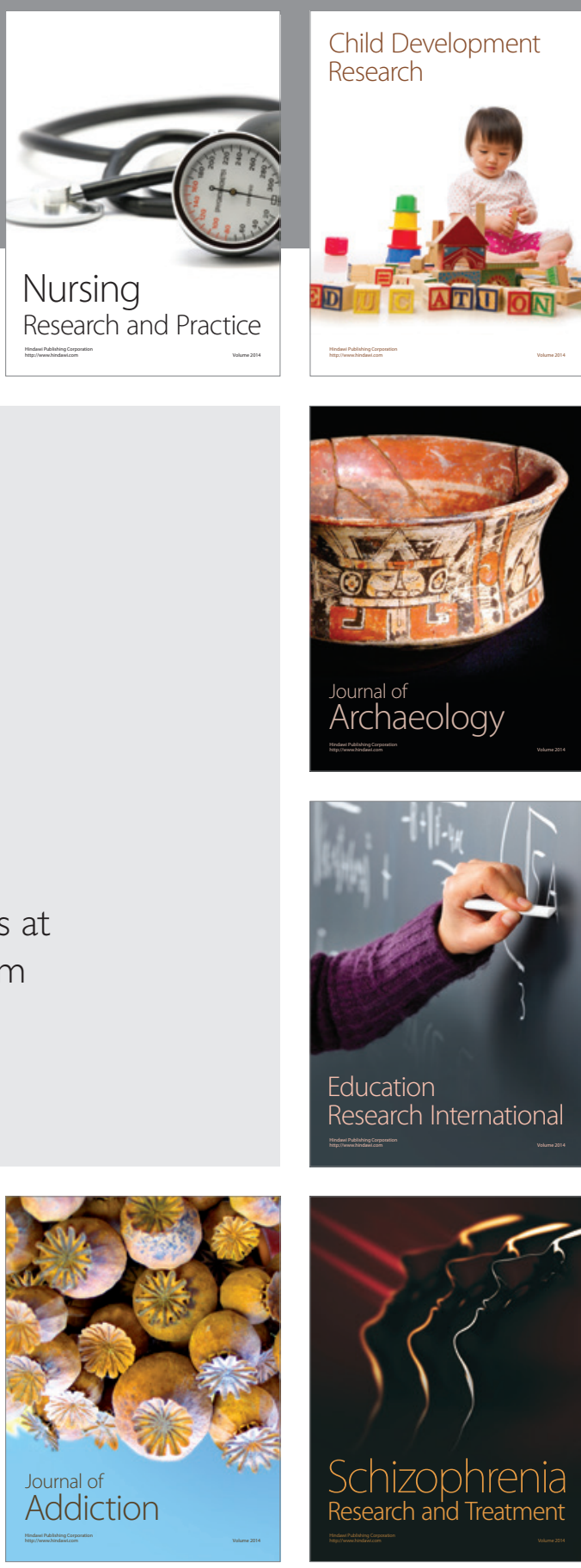

(D)
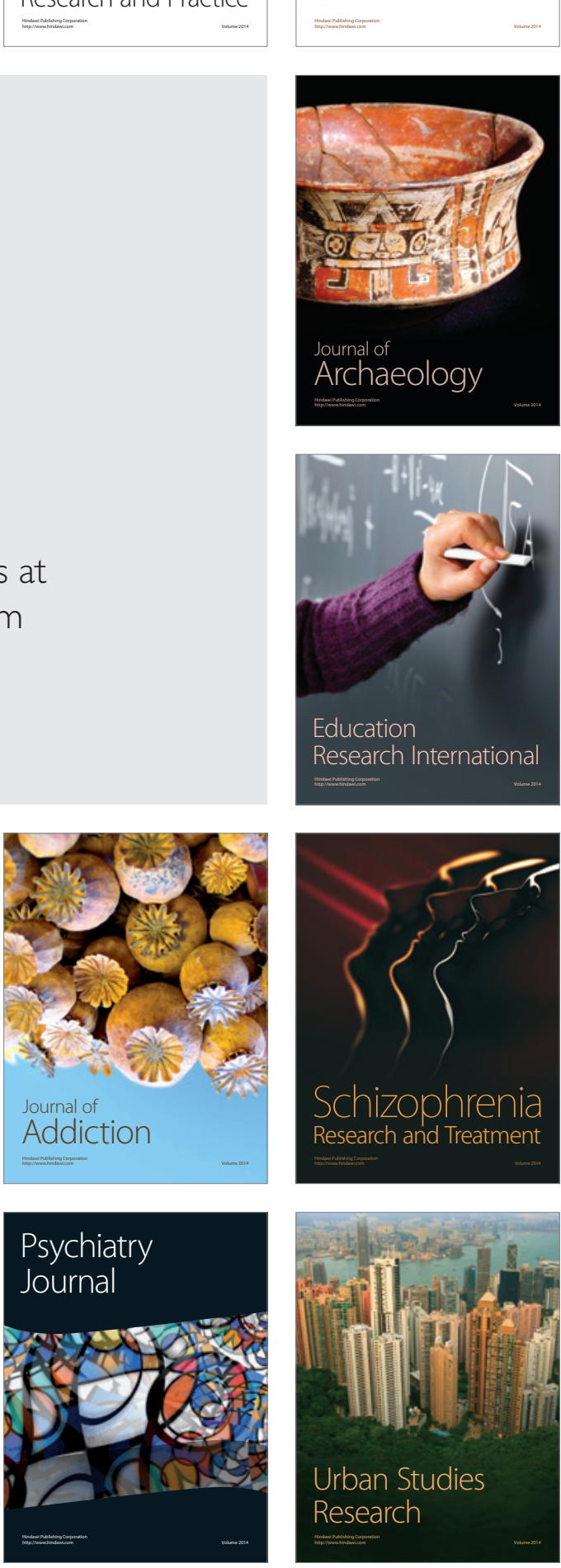